\title{
Cultural Dimensions of Learning: Addressing the Challenges of Multicultural Instruction
}

\author{
Patrick Parrish \\ The COMET Program, USA \\ Jennifer A. Linder-VanBerschot \\ University of New Mexico, USA
}

\begin{abstract}
The growing multicultural nature of education and training environments makes it critical that instructors and instructional designers, especially those working in online learning environments, develop skills to deliver culturally sensitive and culturally adaptive instruction. This article explores research into cultural differences to identify those dimensions of culture that are most likely to impact instructional situations. It presents these in the cultural dimensions of learning framework (CDLF), which describes a set of eight cultural parameters regarding social relationships, epistemological beliefs, and temporal perceptions, and illustrates their spectrums of variability as they might be exhibited in instructional situations. The article also explores the literature on instructional design and culture for guidelines on addressing the cross-cultural challenges faced by instructional providers. It suggests that these challenges can be overcome through increased awareness, culturally sensitive communication, modified instructional design processes, and efforts to accommodate the most critical cultural differences. Finally, it describes the use of the CDLF questionnaire as a tool to illuminate the range of preferences existing among learners and to discover the potential range of strategies and tactics that might be useful for a given set of learners.
\end{abstract}

Keywords: Distance education; online learning; pedagogy; multicultural education

\section{Why Multicultural Education and Training is a Growing Concern}

Numerous factors are converging that make teaching and learning in cross-cultural and multicultural contexts more commonplace. Expanding world trade and globalization of industry, finance, and many professions are creating a world in which cross-cultural interactions occur more frequently than at any time in the past (Friedman, 2007). As well, increasing specialization within many professions has led to a widely dispersed audience for targeted education and 
training. Professionals wishing to stay current or students wanting to develop specialized skills that match the needs of a rapidly changing world demand access to proper educational opportunities, even if this requires international travel or distance learning approaches (Berge, 2007). Simpler and cheaper telecommunications, in particular, fuel a growing willingness to teach and learn across cultures. Advances in Internet technologies and applications make open and distance learning a fully viable alternative to traditional education, creating a natural environment for the development of effective virtual learning communities.

But contrary to the growing flatness that Friedman (2007) reports, cultural diversity remains apparent among learners, perhaps owing to deeply rooted cultural values and modes of thinking that are difficult to separate from learning processes (Nisbett, 2003). A growing appreciation of cultural diversity is demonstrated by more than its acknowledgement and tolerance, but also by a desire to preserve that diversity as a valuable asset for addressing the many challenges faced by the global community now and in the future. Additionally, one can recognize a strong desire to preserve diversity in response to the threat of loss of cultural identity in the face of globalization and because of the benefits of community cohesiveness through unique cultural expression (Mason, 2007).

The growing need for educational access leads students rightly to demand culturally adaptive learning experiences that allow full development of the individual (Visser, 2007). As noted by Pincas (2001), students entering into professional education in a multicultural context not aligned with their own culture can experience significant conflict. This conflict arises not only in regards to incompatible teaching and learning styles, but also because the growing "professional self" struggles to maintain both a connection to the local culture in which the student eventually intends to work and a connection to the learning environment. Accordingly, instructional providers, including instructors and instructional designers, especially those working in online environments and struggling to maintain sufficient presence and student engagement, should develop skills to deliver culturally sensitive and culturally adaptive instruction (Gunawardena \& LaPointe, 2007). This article provides a summary and consolidation of useful existing literature to aid in developing these skills. Although culture has begun to be addressed in the field of Instructional System Design (ISD), it is still too often overlooked or undervalued (Henderson, 1996; Rogers, Graham, \& Mayes, 2007; Thomas, Mitchell, \& Joseph, 2002; Young, 2007). If education and instructional design are inherently social processes (Schwier, Campbell, \& Kenny, 2004), then instructional providers can no longer take a neutral position in developing their courses and materials. For instruction to do the most good for students, instructional providers must be cognizant of the cultures of their learners and how those cultures manifest themselves in learning preferences (Nisbett, 2003).

Cultural sensitivity is not just one-way, however. Instructional providers should be acutely aware of their own culture because their world views cannot be separated from the training that they develop (Thomas, Mitchell, \& Joseph, 2002). They should become cognizant of how their own cultural perspectives are represented in the design decisions they make. Furthermore, instructional providers should examine the assumptions they hold about how learners will and should respond, keeping an open mind for potentially unexpected responses. Moreover, they must 
balance the need to help students adapt to specific professional, academic, and mainstream cultures (which instructors, by proxy, represent) and the need to embrace the culture in which the student is embedded (Henderson, 1996). This is no small challenge.

\section{Sources of Thinking and Behavior}

The sources of influence on thinking and behavior can be seen as existing at several levels, including human nature, culture, and personality (Hofstede \& Hofstede, 2005). When people demonstrate differences or similarities, it is easy to confuse these levels because their influences combine, making them difficult to distinguish. The resulting uncertainty can lead to false assumptions and difficulties in interactions with others. This is just as true in education and training as it is in other life situations.

Hofstede and Hofstede (2005) present these levels as a pyramid, with human nature as the base all people share, and personality as the peak, being unique to the individual. Culture forms an expansive middle portion of the pyramid, reflecting its multiple layers of group interactions (e.g., from national to local community). The authors have chosen to represent these influences differently in Figure 1 to highlight an increased complexity and to emphasize the nature of these constructs as mutually influencing sources of thought and behavior.

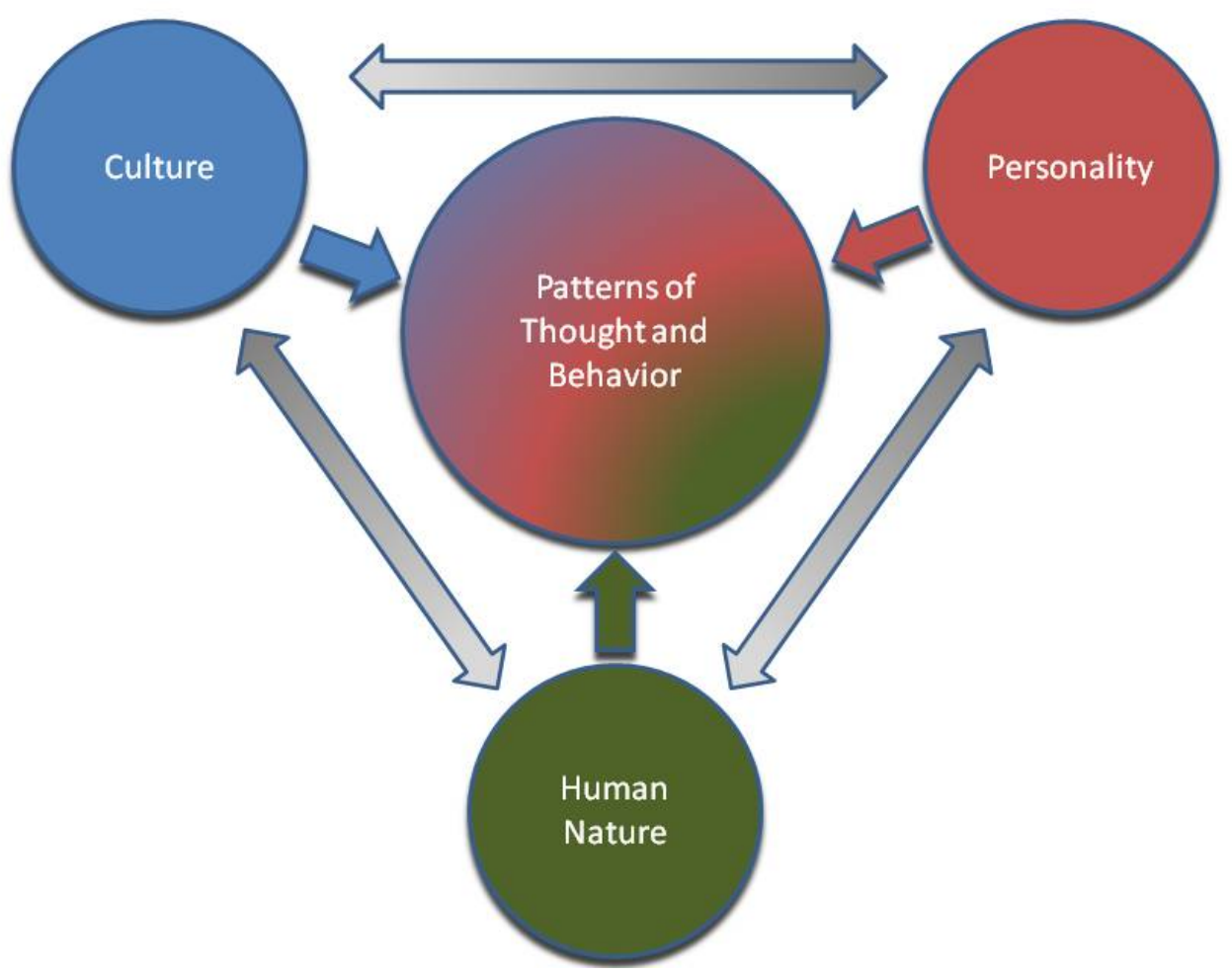

Figure 1. Sources of thought and behavior and their interactions. 
Human nature comprises the assumed commonalities all humans share because they are members of the same species - Homo sapiens. People inherit these ways of thinking and behaving because they result from our genetic makeup and the constraints this places on how they respond to the world. These constraints come in the form of sensory capabilities and other physiological traits, as well as predispositions toward socialization, for example. Of course, the human genetic stream diverges and re-converges over time, so the concept of "species" itself is imperfect. But one can, in practice, see commonalities across the human species. Culture includes those ways of thinking and behaving that are taught by social groups, including family, friends, community, and work colleagues, developed through direct interaction but also through exposure to media (Hofstede \& Hofstede, 2005). Among many other things, culture includes,

... how people express themselves (including shows of emotion), the way they think, how they move, how problems are solved, how their cities are planned and laid out, how transportation systems function and are organized, as well as how economic and government systems are put together and function. (Hall, 1981, pp. 16-17)

Cultural preferences are strongly embedded because humans are highly social creatures with strong needs to fit within our groups. There are many layers of culture, from work and family cultures to community and regional cultures up to national and even international cultures based on shared heritage and language. Culture is learned but is also constrained by human nature.

Unlike human nature, which is inherited, and culture, which is learned, personality is both learned and inherited. Individuals within cultures vary in ways that are as dramatic as the variations across cultures, and one can map similar personality variations across different cultures. This suggests that personality is in part a reflection of the natural variability within human nature and cuts across cultures. But, also, there is no one-to-one correspondence of personalities across cultures due to the blend of cultural and natural influences on personality. Some discernable personalities and even some emotions may be culturally unique (Kitayama \& Markus, 1994).

Together, culture and human nature have a monumental influence on individual personalities, yet people are also willful and creative in their responses to the world, frequently stretching or transcending their natural and cultural inclinations. And even though they are products of their cultures, some individuals ultimately have a profound influence on their cultures; consider the ongoing influence that individuals like Confucius or Plato have had on civilizations over thousands of years. Through processes of natural selection, individuals and cultures may even be seen as influencing human nature over time. In this way, even human nature is in a sense "learned."

Of course, one doesn't have to postulate a person as influential as Confucius to demonstrate the nature of culture as changing through the influence of individuals and groups. Deep-rooted as culture may be, a description of any culture is merely a snapshot of a continually evolving matrix of beliefs, values, and behaviors developed through the creative interactions of its constituents as 
well as through interactions and clashes with other cultures. In addition, while culture is reflected in arts and technologies, it is also influenced by them. The fact that culture is created by the accumulation of historical experience is well acknowledged in education literature through its embrace of cultural-historical activity theory (Cole, 1996).

However, the inevitability of cultural evolution does not suggest that how practitioners carry out cross-cultural interactions in instruction is unimportant. (One might ask, "Why work to preserve culture that will change anyway?”) On the contrary, in this article we argue that respect for preservation of culture is an important value for instructors and instructional designers to hold because they are clearly in the position of social agents having substantial influence on their learners (Schwier, Campbell, \& Kenny, 2004). In other words, prioritizing culture in education and training goes beyond wanting to be effective in promoting knowledge acquisition. It is also an ethical concern.

Fundamentally, when we teach, we are teaching culture. Knowledge, skills, and attitudes are all manifestations of culture and are not somehow immune to it. Moreover, when we teach, we are passing along not only what we know, but how we come to know it as well as the basis for accepting it as useful knowledge, and the values these represent. Teaching and learning are not only embedded in culture, they are cultural transmission in action - the means to culture. In multicultural settings, in particular, this leads to the conundrum posed in the first section that educators must take responsibility to both acculturate students and in the process avoid cultural bias that could impede instructional goals. Potential approaches to this challenge are posed in the upcoming sections.

\section{A Framework for Cultural Differences}

The cultural dimensions of learning framework (CDLF) (Table 1), adapted from the work of Hofstede and Hofstede (2005), Nisbett (2003), Levine (1997), Hall (1983), and Lewis (2006), is useful for understanding the spectrum of cultural differences that impact the teaching and learning enterprise. Where individuals fall along these dimensions impacts both how instructional providers approach their roles and how students view their own roles and expected behaviors. The dimensions do not describe either/or conditions but spectrums along which both cultures and individuals vary. Accordingly, no end of the spectrum should be unrecognizable to the reader, regardless of cultural background. Because humans share a common nature, each person is capable of the entire range of thoughts and behaviors that can arise along each of the dimensions. Research shows that cultural differences can be usefully described along these dimensions but that within any culture individuals will differ in how strongly they display these tendencies.

This framework differs in scope from the framework offered by Reeves (1992), as cited by Henderson, (1996), which begins from the perspective of pedagogical differences; however, the frameworks reach many of the same conclusions. The CDLF touches upon nearly all the dimensions described by Reeves but includes several new dimensions due to its broader starting point and the benefit of new research performed in the intervening years. It also describes these cultural dimensions in more detail. Even so, the CDLF does not pretend to address all potential 
cultural dimensions that might be useful to consider. For example, gender roles and differences in non-verbal communications are treated only indirectly. Cultural complexity and the fundamental role of education and training in the transmission of culture make a comprehensive framework impractical to describe in a single article.

In presenting their model of cultural dimensions, Hofstede and Hofstede (2005) discuss the difference between values and practices as layers of culture. In their terms, cultural values are acquired early in life and are the deepest and most enduring aspects of culture. Cultural practices, on the other hand, are the superficial rituals and norms that are more easily observed. While practices may be reflections of cultural values, they are more subject to change. The most superficial practices are not inevitable outcomes of values; they are often mere trappings that can change without challenging underlying values. In this framework, the eight cultural dimensions represent values. Consequently, the manifested learning behaviors described are more than superficial practices. Instead, they are direct reflections of values, and challenging them may conflict with those underlying values. More research specifically focused on cultural aspects of learning environments is required before this claim can be asserted with full confidence, although compelling research already exists for many of the aspects (e.g., Nisbett, 2003).

The descriptions of eight key cultural dimensions in the CDLF are offered so that culturally based learning differences can be recognized when they manifest themselves. It is not suggested that each of the dimensions needs to be considered and addressed in every instructional design project. However, those involved in a large multicultural instructional undertaking for the first time may find it useful to study the framework to prepare for the potential differences they might encounter among learners. Parrish and Linder-VanBerschot (2009a) offer a survey on culturally based learning preferences, derived from the CDLF, which can also aid in the analysis phase of projects or in the early phases of a course.

Another important use of the CDLF is as a tool for instructional providers to understand better their own cultural biases and to account for them in their practice. Recognizing that one's beliefs and behaviors fall along a spectrum of differences can help increase flexibility in instructional approaches and create stronger empathy for learners. However, because the framework, even with its numerous dimensions, does not begin to capture the cultural diversity that actually exists, unanticipated differences are likely. Note that while no attempt is made here to classify cultures according to these dimensions, the works cited provide substantial demonstration of how specific national and regional cultures vary. This article instead stresses the spectrums of variability rather than the generalized differences between cultures. 
Table 1

The Cultural Dimensions of Learning Framework

\section{Social Relationships}

\section{Cultural dimension Equality and authority}

How is inequality handled? How is status demonstrated and respect given? What interactions are appropriate for those of unequal status?

(Hofstede \& Hofstede, 2005;

Lewis, 2006)

\section{Individualism and collectivism}

Which prevails, the interests of the individual or the interest of the group? To what degree are interpersonal relationships valued?

(Hofstede \& Hofstede, 2005; Nisbett, 2003)

\section{Nurture and challenge}

Which is the more important set of goals, cooperation and security or recognition and advancement? Which achieves better learning outcomes, supportive acts or challenging acts?

(Hofstede \& Hofstede, 2005)

How this dimension is manifested in learning situations More equality More authority

Teachers treated as equals to be engaged and even challenged

Students take responsibility for learning activities

Teachers are solely responsible for what happens in instruction

Dialogue and discussion are critical learning

The teacher is the primary communicator activities

\section{More individualistic}

Expectation that students speak up

Learning how to learn (cognitive skill) is primary (individual growth)

Expression of student's point of view is valuable component of learning

Hard work is motivated by individual gain

\section{More nurturing}

Average is used as the norm

All students are praised

Collaboration is cultivated

Failure is a growth opportunity

More modesty

Seek good relationships and security

\section{More collectivist}

Students speak up in limited situations

Learning how to do (content knowledge) is primary (social growth)

Student expected to accommodate teacher's point of view

Hard work is motivated by the greater good

\section{More challenging}

Best student is used as the norm

Only excellence is praised

Competition is cultivated

Failure is a highly discouraged, and can be considered disastrous

More assertiveness

Seek challenge and recognition 


\section{Epistemological Beliefs}

\section{Cultural dimension Stability seeking and uncertainty acceptance} How is uncertainty dealt with? Is it avoided or accepted? Is structure assumed more important than flexibility? What is the status of knowledge - established or in a process of development? (Hofstede \& Hofstede, 2005; Nisbett, 2003)

\section{Logic argumentation and being reasonable}

How are arguments developed? Which is more important, logical consistency or practical outcomes? How is disagreement managed?

(Nisbett, 2003)

\section{Causality and complex systems (Analysis and holism)} How is causality assigned typically? Is it assigned to a single, most likely source, or is it assigned to the broader context? (Nisbett, 2003)
How this dimension is manifested in learning situations

\begin{tabular}{|c|c|}
\hline More stability seeking & More uncertainty acceptance \\
\hline Structured learning activities & $\begin{array}{l}\text { Learning activities more open-ended (discussions, } \\
\text { projects) }\end{array}$ \\
\hline Focus on getting right answers & Focus on process and justified opinions \\
\hline Ambiguity to be avoided & Ambiguity is a natural condition \\
\hline Teachers expected to have the answers & Teachers can say “I don’t know” \\
\hline Single textbooks or teacher authority & Many resources used \\
\hline $\begin{array}{l}\text { Luck is a factor in student success (e.g., guessing } \\
\text { the right things to study for the test) }\end{array}$ & $\begin{array}{l}\text { Demonstrated ability to think is the key to } \\
\text { academic success, not right answers }\end{array}$ \\
\hline More stressed & Less stressed \\
\hline
\end{tabular}

\section{More logical \\ Focus on logical argumentation to find truth \\ Insistence on single truths based on logical reasoning}

Debate/argumentation is a learning activity

Being right is most important

Willingness to challenge others when the teacher/students are presumed wrong or being

.
inconsistent

\section{More reasonable}

Focus on achieving practical and socially acceptable outcomes

Acceptance of multiple truths based on experience

Consensus building is a learning activity

Being virtuous is most important

Acceptance of contradictions for the sake of continuing, harmonious dialogue

\author{
More focus on causality \\ More goal orientation expected of learners \\ Knowledge tied to cause-effect explanations \\ Focus on stable knowledge and rules \\ Learning success or failure attributed to student \\ characteristics
}

\section{More focus on systems and situations}

More willing to work within situational constraints

Knowledge tied to explanations of systems and situations

Focus on evolving and situational knowledge

Learning success or failure attributed to the situation 


\section{Temporal Perceptions}

\section{Cultural dimension \\ Clock time and event time}

Do people conform to an external measure of time, or do they allow the event at hand to unfold on its own time? Which are more important, deadlines or relationships?

(Levine, 1997)

\section{Linear time and cyclical time}

Do people see time as a path and see goals as necessary destinations, or do they see time as a pattern of interlocking cycles into which they step in and out over the course of a life? (Hall, 1983; Lewis, 2006)

\section{How this dimension is manifested in learning situations}

\section{More clock focus}

Instructional activities start and stop promptly

Meetings outside of class time are limited to strict

schedules

Strict deadlines and consequences for missing them

Likes procedures

Learners work quietly toward planned ends

\section{More event focus}

Instructional activities are allowed to continue as long as they are useful

Boundaries between class and outside class time more fluid

Work continues toward improvements with less regard for deadlines

Willing to bypass procedures

Learners are talkative and expressive and may ignore plans

\section{More cyclical time}

One adapts to time
Time is to be managed

Learning proceeds along a linear path with clear prerequisites and milestones

Goal setting is essential to learning

Time is not to be wasted, actions should be quick and decisive if one cares about achievement

Opportunities are not to be wasted. Chances don't present themselves twice

The past is irrelevant. Future goals are what are important.

Repetition can be seen as a being in a "rut" (not progressing)

Students want to see immediate relevance
Learning is seen as practice toward slowly increasing perfection

Goals are secondary, one adapts to the situation to draw from it as much as possible

Time exists for observation and reflection, rushing is counter-productive to achievement

Because time is a series of cycles, opportunities recur. When they do, one may make wiser decisions

The past is influential since cycles repeat. One carries the past forward.

Repetition is valuable for learning

Students may be more patient to discover relevance 


\section{Cross-Cultural Challenges for Instruction}

People make false assumptions when they attribute ways of thinking and behavior to the wrong source of influence (human nature, culture, or personality). They may wrongly assume that a particular behavior is a manifestation of personality, perhaps making a value judgment about that individual, when the behavior is actually driven more from the cultural level. Conversely, they may over-generalize conclusions about a particular culture from a few individuals when actually their behaviors are strongly personality driven. Perhaps the most common false assumption is when people take their own cultural ways of thinking and behaving as representative of human nature and therefore the "right" way to think or behave. For example, instructional providers may assume that they need to teach those from other cultures to adopt new learning behaviors to think and learn properly. The CDLF may aid in avoiding such false assumptions.

Humans are highly adaptable, and the situational influences on thought and behavior are significant (Lemke, 1997). So observing how a person behaves in one situation is not necessarily indicative of how they will behave in another. In addition, people are able to compensate for their cultural conditioning when they find themselves participating in another culture by adopting the behaviors they begin to see as appropriate to that culture. These cases can also lead to additional false assumptions that are more difficult to avoid.

The unique challenge for instructional providers is to understand which learning behaviors are based on deeply entrenched cultural values that should not be challenged and which behaviors are more superficial practices that can be challenged for the sake of promoting learning. In addition, other challenges include (a) accepting that research-based instructional strategies are also culturebased and may be at times inappropriate, (b) knowing which instructional activities will be most effective for a particular group of students, and (c) deciding how instructional strategies should be adapted in cross-cultural and multicultural situations. The existing literature that will aid in addressing these challenges is growing but still limited.

\section{Addressing the Challenges of Multicultural Education and Training}

Many of the challenges to practicing education and training in multicultural contexts have been put forth in the preceding pages with few direct recommendations for changing practice. The challenges, restated more succinctly, are these:

1. Understanding and appreciating the cultural differences of students in order to make the appropriate instructional decisions that will enhance their learning;

2. Becoming aware of one's own cultural preferences for what they are and not assuming they represent the "right" way to think;

3. Determining which student behaviors represent cultural values and are therefore less prone to modification to accommodate the instructional situation;

4. Accepting the dual responsibility of educators to acculturate and respect individual student cultural backgrounds; and 
5. Accepting that research-based instructional strategies are also culture-based and therefore may be at times inappropriate or in need of adaptation.

The CDLF can be used to help address the first three challenges. Challenges 4 and 5 require additional effort toward a reflective practice that the CDLF also indirectly encourages and, hopefully, stimulates. This section summarizes several additional ideas and perspectives that can lead to effective multiculturally sensitive practice.

\section{Awareness}

Instructional providers must become more knowledgeable about the cultural differences existing among the learners they serve. With an unpredictable learner population in most settings, perhaps especially in open and distance learning settings, instructional providers can no longer make overarching judgments about the demographics of their learners before having the opportunity to interact with them (Lea \& Goodfellow, 2003). Therefore, instructors and IDs should carefully consider the learner population during the analysis phase of any instructional design or planning effort (Edmunson, 2007; Young, 2008).

Unfortunately, culture is often overlooked because the analysis phase of instructional design is one of the most commonly skipped phases. Thomas, Mitchell, and Joseph (2002) remind us that, "culture is so much a part of the construction of knowledge that it must underpin not only the analysis phase but all phases of the design process" (p. 41). Thus it is essential that instructional providers continue to familiarize themselves with the learners' cultures throughout the implementation phase and even through the evaluation stage. They might consider including a cultural expert as part of the design team or asking a representative participant to help plan a course, training event, or product before implementation occurs (Thomas, Mitchell, \& Joseph, 2002; Young, 2008).

Of course, educators must also become more aware of the cultural biases embedded in their own teaching and instructional designs, including the selection of instructional activities, their presentation styles (including both verbal and non-verbal communications), and their expectations of students. Ignorance of these biases could prevent them from seeing opportunities for more effective avenues of interaction with learners. The CDLF presented in the previous section is meant to increase both kinds of awareness. Reviewing the framework while considering current and past students, as well as one's own practice, can help create a higher degree of awareness and sensitivity to cultural differences when they emerge.

To aid in using the framework, the authors have developed a questionnaire based on the CDLF that can illuminate the range of preferences existing among learners (Parrish \& LinderVanbershot, 2009a). The questionnaire is not intended to be used to make final judgments about individuals but to point to the potential range of strategies and tactics that might be useful for a given set of learners. It can be used in at least two ways. First, instructional providers may complete the survey themselves to identify their personal learning (and teaching) preferences. This will help them become aware of their biases as they design and deliver instruction. The 
second use is to have learners complete the survey before instruction or instructional development begins. Students can self-analyze or, if there is time, results can be analyzed as a group (using the CDLF questionnaire analysis form, Parrish \& Linder-Vanbershot, 2009b), which has the additional benefit of encouraging understanding between learners. The results can also guide instructional providers in adapting instruction to meet the learning preferences of learners. (Note that the CDLF questionnaire has not yet been used in a research context. It is offered here as a tool for practice.)

\section{Communication}

To aid in increasing awareness, instructional providers should clearly communicate the cultural bases of their approaches to instruction and should provide opportunities for students to voice their own cultural proclivities. Creating opportunities for discussion about learning preferences should be a first step in determining the direction an instructional event should take. Gunawardena, Wilson, and Nolla (2003) suggest that dialogue and communication, leading to negotiation of the instructional details, are the central factors in creating a culturally relevant design. Of course, for those who develop self-pace materials or never actually meet their learner audiences, communication may be limited to the interactions that occur during a learner analysis phase. But even in these instances of remoteness, communication can be extended by providing opportunities for feedback via surveys and evaluation tools.

The CDLF questionnaire results also can be a tool to stimulate class discussion about learning preferences; it can create a venue for an instructor to justify the instructional strategies employed in a course, or it can offer a structure for negotiation for those course activities that remain negotiable.

\section{Process}

Several authors have suggested amendments and alternatives to traditional instructional systems design (ISD) models to better incorporate consideration of cultural diversity. Thomas, Mitchell, and Joseph (2002) suggest adding a "third dimension" to the traditional ADDIE process (analysis, design, development, implementation, and evaluation) that includes pervasive (a) questioning of design intentions throughout to ensure designers remain culturally sensitive, (b) interaction with the intended audience to better understand their needs and preferences, and (c) introspection about beliefs and attitudes toward other cultures.

Edmundson (2007) offers the CAP (cultural adaptation process) model as an expansion of the traditional needs assessment and learner analysis phases of an instructional design process (part of the "A" of ADDIE). This model includes several levels of cultural analysis, including consideration of those factors that impact content, pedagogical, and media choices, and identification of appropriate adaptation strategies. While focused on needs assessment, CAP also implies recommendations for formative evaluation. Rogers, Graham, and Mayes (2007) also point to the need for a much expanded analysis phase for cross-cultural situations. 
Gunawardena, Wilson, and Nolla (2003) emphasize interaction and negotiation in their adaptive, meaningful, environmental-based architecture for online course design (AMOEBA). This model suggests a highly participatory role for students in course decisions, including making choices regarding language (when feasible), interface formats, communication channels, instructional activities, and instructional methods.

Finally, Young (2007; 2008) offers the culture based model (CBM), which includes consideration of culture throughout the instructional development process. The CBM is less a process-based model and more an elaborate framework for culturally sensitive instructional design activity that describes (a) questions asked to help maintain an audience focus, (b) project management recommendations, (c) design team roles, (d) the use of assessment and review, (e) prescriptions for decision making processes, (f) appropriate learner-centered learning outcomes, (g) culturally sensitive design factors that must be considered, and (h) skills required of the design team.

These process recommendations have three things in common:

- Consideration of cultural differences in each phase of the design process, with extra attention occurring during the analysis phase;

- Pervasive reflection and a willingness to modify one's first inclinations about the instructional design; and

- Interaction with students or student representatives during design (user-centered design) (Carr-Chellman, 2006).

\section{Accommodation}

Awareness, communication, and process changes will lead to increased knowledge about cultural diversity, but the need remains to use that knowledge in making design decisions to address diversity. This section describes several ways in which instruction can provide opportunities for learners to apply their culturally dependent approaches to learning, effectively allowing a pedagogical "localization." Yet, the degree to which an instructor and ID can adapt instruction, given time and budget constraints, organizational desires for consistency, and the need to acculturate students into professional and mainstream cultures, is limited. Which adaptive design choices should be made requires careful consideration.

In single cross-cultural instances, in which instruction is being designed for a culturally homogeneous set of students but from a culture different than that of the instructional provider, accommodation should include as much adaptation as possible based on the cultural analysis, without compromising the fidelity of the content and underlying necessary instructional principles (Castro, Barrera Jr., Martinez Jr., 2004; Rogers, Graham, \& Mayes, 2007). Of course, this assumes that instructional providers can transcend their cultural inclinations to identify the instructional elements that require fidelity as well as the changes that would corrupt the instructional intent and the comfortable trappings that could be sacrificed for the sake of the students. For example, will a problem-based learning activity require the same student roles as were used in a previous implementation? Will each class be predominately discussion based, or 
should there be some lecture/presentation component that provides increased guidance? To what degree should the instructor expect students to express personal views or to ask challenging questions, and to what degree is that also the duty of the instructor? Should a strict schedule be enforced, or should some flexibility be built in?

Most authors suggest that accommodation in multicultural situations be achieved by offering students alternative choices in learning activities and instructional formats (Irvine \& York, 1995; McLoughlin, 2001). Some choices may be more costly than others to include, so the use of alternatives must be based on how deeply rooted the cultural preferences are (the degree to which ignoring them will affect learning) and on how easy the alternatives are to implement (which will vary by instructional mode). The alternatives that will be most critical to learning success can be discerned during the cultural analysis of learners, which can be guided by the CAP, CBM, or AMOEBA models, as well as the CDLF offered here. The CDLF questionnaire and analysis form (Parrish \& Linder-Vanbershot, 2009a; 2009b) might be useful in determining the degree to which learners feel they are represented on each dimension, which would be a good indicator of how critical that dimension is for determining alternatives.

Knowing which types of adaptations instruction should undergo based on cultural analysis is difficult and calls for additional research. The details offered in the CDLF can be of help in stimulating design adaptations, but it offers no direct advice for design decisions. These must be derived by the instructional provider based on a deeper understanding of a particular group of learners. However, detailed case studies of adaptations are worth studying as best practices.

Henderson (1996), who espouses a "multiple cultural” approach that embraces both predominant and minority cultures, describes a module design that supports both constructivist and instructivist orientations, allowing freedom for students to follow either a prescribed path or one of their own choosing. Arya, Margaryan, and Collis (2003) describe an instructional product that offers alternatives in both content and learning activities in a blended learning course on workplace problem-solving, a skill area which the CDLF suggests should reveal a high degree of cultural differences. Edmundson (in press) describes how strategic modularization can achieve a similar effect for multinational organizations, who desire to reuse core content while supplying interchangeable cross-cultural learning objects (XCLOs) for key content and learning activities that call for cultural adaptation. Edmundson also argues for careful use of "low-context" content (Hall, 1983), content that avoids language, idioms, and references that assume a high degree of cultural context or that includes a clear description of that context, which can avoid the need for unnecessary adaptation.

One might argue that research-based educational practices transcend culture or are culture-neutral and that it is simply good practice to use what research tells us works, regardless of cultural differences. But of course research itself is culturally bound, not only by the situations in which it is performed and the availability of participants, but also by the chosen research questions, research designs, and what is considered acceptable as evidence. In fact, the existence of longheld cultural differences exhibited by foreign but successful cultures should make us question the broad validity of any research-based practices. At a minimum, one should reflect to determine the 
underlying operational principles of any particular research-based instructional strategy (Gibbons, 2009) and decide whether some of its prescribed methods and conditions can be modified to work more effectively within other cultural frameworks (Rogers, 2007).

\section{Remaining Questions and Conclusions}

The CDLF could prove useful in multiple contexts. This article presents the framework and questionnaire as tools for practice, but the CDLF might also support research, for example to determine which preferences appear to cluster together or which appear to be common among a particular group of learners. Many questions remain, the answers to which may help provide additional guidance for the utilization of the CDLF.

- Which cultural dimensions are most important to consider in adapting instruction? Which offer more forgiveness if ignored?

- Which dimensions provide the most difficulty for adaptation? Which can be accommodated via easily implemented adaptations?

- Because some of these dimensions likely suggest new considerations for educators, what are the strategies that can be used to create adaptations? At what point(s) in the ADDIE process is it most important to consider these adaptations?

- Do the extremes in some dimensions represent incompatible approaches, while others might peacefully coexist?

- What degree of variation exists among culturally homogeneous students in comparison to multicultural groups? To what degree can the framework help in either situation?

- What roles do these cultural dimensions (and others not identified here) play in the choice and application of instructional technologies?

- How might prominent instructional strategies, like problem-based learning, be adapted to fit in a multicultural context? Which cultural dimensions are impacted when applying such fundamental strategies?

- How do generational differences of both students and educators affect location along the dimensions? What role does the age of students play in determining the cultural rootedness of learning preferences?

The ability to accommodate culturally based learning differences is becoming an increasingly critical skill in this time of rapid globalization and technology-influenced cross-cultural interactions. This paper contributes to the literature on cultural considerations of teaching and learning by exploring the basis of culture and the dimensions that most directly impact the teaching and learning enterprise. The CDLF provides a rich tool for analyzing the differences in learning preferences, which, when combined with process-oriented strategies for culturally sensitive adaptation, can help instructional providers become more effective in cross- and multicultural situations.

It has been suggested that being involved in multicultural exchanges can make one more sensitive to communication patterns because the old, reliable patterns are no longer effective. For example, 
one may become a better listener and a more careful communicator because first assumptions are more suspect. One becomes more conscious of the unspoken intentions, and perhaps unintended messages, embedded in communications. This increased awareness may improve overall communication skills within and across cultures (Hall, 1981).

Arya, Margaryan, and Collis (2003) ponder whether cultural accommodation in instruction "suggests stereotyping which can lead to new dilemmas" (p. 41). Future research must respond to this question because the resulting compartmentalization could lead to results counter to the goals of instruction, which include opening students' minds to change and new ideas. Thomas (2003) reminds us that instructional providers need to be aware of both the intended and unintended consequences of their instructional designs and that all consequences should be researched and discussed. In the end, research into the multicultural education and training challenges may lead to greater wisdom for all instructional situations. 


\section{References}

Arya, K., Margaryan, A., \& Collis, B. (2003). Culturally sensitive problem solving activities for multi-national corporations. TechTrends, 47(6), 40-49.

Berge, Z. L. (2007). Training in the corporate sector. In M. G. Moore (Ed.), Handbook of distance education $\left(2^{\text {nd }}\right.$ ed.). Mahwah, NJ: Lawrence Erlbaum Associates.

Carr-Chellman, A. A. (2006). User design. Mahwah, NJ: Lawrence Erlbaum Associates.

Castro, F. G., Barrera Jr., M., \& Martinez Jr., C. R. (2004). The cultural adaptation of prevention interventions: Resolving tensions between fidelity and fit. Prevention Science, 5(1), 4145.

Cole, M. (1996). Cultural psychology: A once and future discipline. Cambridge, MA: Harvard University Press.

Edmundson, A. (2007). The cultural adaptation process (cap) model: Designing e-learning for another culture. In A. Edmundson (Ed.), Globalized e-learning cultural challenges (pp. 267-290). Hershey, PA: Idea Group, Inc.

Edmundson, A. (in press). Cross cultural learning objects. In A. Edmunson (Ed.), Cases on globalized and culturally appropriate e-learning: Challenges and solutions. Hershey, PA: IGI Global.

Gibbons, A. S. (2009). The value of the operational principle in instructional design. Educational Technology, 49(1), 3-9.

Gunawardena, C. N., Wilson, P. L., \& Nolla, A. C. (2003). Culture and online education. In M. G. Moore \& W. G. Anderson (Eds.), Handbook of distance education (pp. 753-775). Mahwah, NJ: Lawrence Erlbaum Associates.

Gunawardena, C. N., \& LaPointe, D. (2007). Cultural dynamics of online learning. In M. G. Moore (Ed.), Handbook of distance learning ( $2^{\text {nd }}$ ed., pp. 593-607). Mahwah, NJ: Lawrence Erlbaum Associates.

Hall, E. T. (1981). Beyond culture. New York: Random House.

Hall, E. T. (1983). The dance of life. New York: Doubleday.

Henderson, L. (1996). Instructional design of interactive multimedia: A cultural critique. Educational Technology Research \& Development, 44(4), 85-104. 
Hofstede, G., \& Hofstede, G. J. (2005). Cultures and organizations: Software of the mind (2 ${ }^{\text {nd }}$ ed.). New York: McGraw-Hill.

Irvine, J. J., \& York, D. E. (1995). Learning styles and culturally diverse students: A literature review. In J. A. Banks (Ed.), Handbook of research on multicultural education (pp. 484497). New York: Macmillan.

Kitayama, S., \& Markus, H. R. (Eds.). (1994). Emotion and culture: Empirical studies of mutual influence. Washington, D.C.: American Psychological Association.

Lea, M., \& Goodfellow, R. (2003). Supporting academic writing in a global online environment. Paper presented at the European Association of Teachers of Academic Writing, Budapest, Hungary.

Lemke, J. L. (1997). Cognition, context, and learning: A social semiotic perspective. In D. Kirshner \& J. A. Whitson (Eds.), Situated cognition: Social, semiotic, and psychological perspectives (pp. 37-55). Mahwah, NJ: Lawrence Erlbaum Associates.

Levine, R. (1997). A geography of time. New York: Basic Books.

Lewis, R. D. (2006). When cultures collide: Leading across cultures ( $3^{\text {rd }}$ ed.). Boston: Nicholas Brealey International.

Mason, R. (2007). Internationalizing education. In M. G. Moore (Ed.), Handbook of distance education ( $2^{\text {nd }}$ ed., pp. 583-591). Mahwah, NJ: Lawrence Erlbaum Associates.

McLoughlin, C. (2001). Inclusivity and alignment: Principles of pedagogy, task and assessment design for effective cross-cultural online learning. Distance Education, 22(1), 7-29.

Nisbett, R. E. (2003). The geography of thought: How Asians and westerners think differently...And why. New York: Free Press.

Parrish, P. E., \& Linder-VanBerschot , J.A. (2009a). The cultural dimensions of learning framework questionnaire. Retrieved from http://homes.comet.ucar.edu/ pparrish/index.htm.

Parrish, P. E., \& Linder-VanBerschot, J.A. (2009b). The CDLF questionnaire analysis form. Retrieved from http://homes.comet.ucar.edu/ pparrish/index.htm.

Pincas, A. (2001). Culture, cognition, and communication in global education. Distance Education: An International Journal, 22(1), 30-51.

Rogers, C. P., Graham, C. R., \& Mayes, C. T. (2007). Cultural competence and instructional 
design: Exploration research into the delivery of online instructoin cross-culturally. Educational Technology Research \& Development, 55(2), 197-217.

Schwier, R. A., Campbell, K., \& Kenny, R. (2004). Instructional designer's observations about identity, communities of practice and change agency. Australasian Journal of Educational Technology, 20(4), 69-100.

Thomas, M., Mitchell, M., \& Joseph, R. (2002). The third dimension of ADDIE: A cultural embrace. TechTrends, 46(2), 40-45.

Thomas, M. K. (2003). Designer's dilemmas: The tripartheid responsibility of the instructional designer. TechTrends, 47(6), 34-39.

Visser, J. (2007). Learning in a global society. In M. G. Moore (Ed.), Handbook of distance education ( $2^{\text {nd }}$ ed.). Mahwah, NJ: Lawrence Erlbaum Associates.

Young, P. A. (2007). The culture based model: A framework for designers and visual id languages. In L. S. Botturi \& L. Todd (Eds.), Handbook of visual languages for instructional design (pp. 52-75). Hershey, PA: Information Science Reference.

Young, P. A. (2008). The culture based model: Constructing a model of culture. Educational Technology \& Society, 11(2), 107-118.

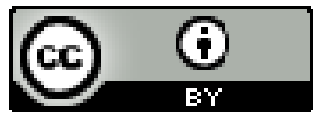

